\title{
PRENSA Y FILIBUSTERISMO EN LOS SUCESOS DE 1911
}

\author{
Por \\ Marco Antonio Samaniego López*
}

\begin{abstract}
RESUMEN
Durante el siglo pasado y mediados del presente, se hizo manifiesto el interés expansionista de empresarios norteamericanos que voltearon sus ojos hacia su frontera sur, en especial hacia Baja California. Basado en un exhaustivo trabajo de revisión hemerográfica de los principales diarios de la época, se realiza un recorrido por los diferentes sucesos que demuestran el continuo asedio de que fue objeto nuestra península y de las diversas posturas que adoptó el capital norteamericano ante los intentos de anexión de este territorio, así como la respuesta que dieron los habitantes de la región. Todo esto enmarcado en los acontecimientos históricos del movimiento magonista y la revolución mexicana.
\end{abstract}

\begin{abstract}
During the last century, and in the mid-part of the present one, expansionist interests were manifested by North American impresarios who cast their eyes toward their suthern frontier, and especially toward Baja California. This article, based on an exhaustive study of the principal newspapers of the era, gives a guided tour of past events showing the continuous siege laid to our peninsula, and the various postures adopted by North American capitalists in their attempt to annex this territory, as well as the answer they received from the people of the region. All this, within the historical framework of the Magonista movement and the Mexican Revolution.
\end{abstract}

Desde principios del siglo XIX y hasta mediados del XX, la península de Baja California fue un punto de atención de los intereses expansionistas de empresarios de Estados Unidos. Se trata de una larga historia en la que los cambios de gobernantes en México y las diferencias internas en la política de los Estados Unidos, que se reflejaron durante la guerra de Secesión (1860-1865), fueron condicionantes permanentes que incidieron

* Investigador del Instituto de Investigaciones Históricas de la Universidad Autónoma de Baja California. 
en el hecho de que la península fuera continuamente asediada por empresarios norteamericanos sin éxito alguno (Keith Chamberlain, 1949:512). Lo despoblado de la región, fue uno de los factores que despertó mayor interés de ciertos individuos o grupos.

En el porfiriato, durante la Revolución Mexicana y en los años posteriores, diversos factores contribuyeron a que el número de habitantes aumentara en la región de forma paulatina. Esta población llegó de varios estados de la república y de otros países, debido a las inversiones que se realizaron, principalmente capitalistas norteamericanos y de algunos mexicanos que lograron por diferentes medios establecer sus propios negocios o pequeñas industrias (Piñera, 1983:284-496).

A pesar de ello, la insistencia de la anexión de la península a los Estados Unidos durante fines del siglo XIX y hasta la cuarta década del XX fue evidente por razones estratégicas y militares. Las solicitudes de anexión de la península fueron constantes por parte de algunos empresarios norteamericanos, mientras que otros, principalmente los que tenían sus inversiones en Baja California, buscaron que la anexión no se realizara, ya que sus intereses eran más favorecidos por el gobiemo mexicano - hasta finales de los años treinta- que por el de los Estados Unidos. El caso más notorio fue el de la Colorado River Land Company, en el valle de Mexicali, empresa que pudo desarrollar el área basándose en el trabajo de asiáticos y en el peonaje asalariado de mexicanos.

Los intereses opuestos de capitalistas estadounidenses en Baja California se hicieron manifiestos en repetidas ocasiones. En el presente trabajo se pretende demostrar lo anterior tomando como base algunos periódicos de California, Estados Unidos, que en gran medida reflejaron las diferentes posturas existentes sobre nuestra península. En especial, comentaremos sobre el Calexico Daily Chronicle, editado por Otis B. Tout, diario que perteneció a la cadena de William Randolph Hearst, quien tuvo como principales diarios el San Francisco Examiner y Los Angeles Examiner. Otro de los capitalistas que mencionaremos es el general Harrison Gray Otis, quien junto con su yerno, Harry Chandler, apareció al frente del influyente periódico Los Angeles Times, así como de la Colorado River Land Company, empresa que desde 1904 era propietaria de más de 300000 hectáreas en el valle de Mexicali. John D. Spreckels, dueño desde 1890 del San Diego Union, y con inversiones en el ferrocarril, es también otro de los que nos ocuparemos, lo mismo que de E.W. Scripps, editor del San Diego Sun, diario que abiertamente en 1889, 1902, 1904 y 1911 demandó la anexión de la península a los Estados Unidos.

Los mencionados periódicos y sus propietarios tuvieron una notable presencia durante 1911, año en el que una fuerza armada organizada en el 
sur de California, formada en una primera etapa por mexicanos y posteriormente por una mayoría de extranjeros, básicamente estadounidenses, ingresó al Distrito Norte de la Baja Califomia con la intención inicial de realizar una revolución, pero que debido a las circunstancias que rodearon el hecho - entre ellas las intenciones de los periódicos californianos- los habitantes de Baja California, así como mexicanos que vivían en California, consideraron que se trataba de una invasión filibustera y colaboraron en distintas formas para defender el territorio nacional. Esto último ha suscitado polémica entre diversos estudiosos que han tratado el tema, ya que quienes venían al frente del movimiento armado estaban directamente relacionados con el Partido Liberal Mexicano, y por tanto, con Ricardo Flores Magón, a quien la historiografía oficial rescató años después de su muerte y le otorg $\delta$ el adjetivo de "precursor de la Revolución Mexicana" facilitando así la amalgama de los personajes que se destacaron en el movimiento armado que inició en 1910. Considero que este aspecto por sí solo requiere de un amplio trabajo que trataremos de desarrollar posteriormente. Lo que aquí señalaremos es cómo la revolución magonista se vio entremezclada con los intereses de los capitalistas norteamericanos, y si bien no existía una relación entre Flores Magón y los empresarios californianos, los intereses de estos últimos influyeron en el movimiento armado, unos con la intención de convertirlo en un movimiento filibustero, y otros por censurar lo que consideraban un acto de vandalismo debido a que se afectaban directamente sus inversiones. Considero relevante el papel que juegan los periódicos califomianos, debido a que incidieron en los acontecimientos y también porque intentaron que el movimiento tomara el curso que les convenía.

De igual manera, varios de los estudios realizados sobre 1911, han tenido como sustento la información que brindaran los perí́dicos californianos, sin considerar las posturas de los mismos durante el movimiento y que por tanto contribuyeron a formar la imagen de ladrones y revoltosos, como en los periódicos de Gray Otis, o el de verdaderos revolucionarios, como los de Hearts, con la intención de que más simpatizantes norteamericanos se sumaran al movimiento y posteriormente anexar la península 0 una parte de ella a los Estados Unidos.

En primer lugar, se presentará una síntesis de los sucesos de 1911 en Baja California, posteriormente se describirá la postura del Calexico Daily Chronicle, y finalmente, se mencionará una relación de acontecimientos anteriores y posteriores a 1911, en los que los intereses norteamericanos en la península se enfrentaron entre sí, unos con la intención de propiciar la anexión de Baja California y otros para que ésta siguiera como parte de México. 


\section{SÍNTESIS DEL MOVIMIENTO ARMADO}

El 29 de enero de 1911, un grupo de mexicanos tomaron a nombre del Partido Liberal Mexicano el poblado de Mexicali. José María Leyva y Simón Berthold eran los cabecillas del movimiento. La mayoría de la población del lugar se fue a vivir a Caléxico, California, donde permaneció hasta el mes de junio de 1911, sin intención de unirse a los magonistas. Algunos autores especulan acerca de cuál era la intención de Flores Magón; de acuerdo con lo que él mismo escribió meses después, trataba de dar el primer paso de una revolución anarquista de carácter internacional (Flores Magón, 1985:306-312).

Celso Vega, jefe político y militar que residía en Ensenada, cabecera política del distrito, organizo una marcha hacia Mexicali para enfrentarse a los ocupantes del poblado fronterizo. El 15 de febrero se realizo el primer combate a las afueras de Mexicali, resultando triunfador el grupo comandado por Berthold y Leyva. Vega fue herido de bala en tres ocasiones y lo llevaron a Ensenada para su rehabilitación. En los siguientes meses, el jefe político permanecio inactivo en el aspecto militar, y fue hasta fines de junio cuando encabez $\sigma$ el último combate en la población de Tijuana que marco la salida del grupo armado, el que para entonces estaba formado en su mayoria por norteamericanos y prácticamente no obedecía las órdenes de Ricardo Flores Magón (Blaisdell, 1992;133-240).

Los habitantes mexicanos de Ensenada y Tijuana se organizaron para la defensa de lo que consideraban otro intento de invasión filibustera. Más adelante señalaremos los antecedentes de ello. Cabe señalar que el propio cónsul norteamericano en Ensenada, George B. Schmucker, contribuyó a fomentar la idea del filibusterismo cuando escribio solicitando ayuda a su gobiemo ya que, según él, empresarios estadounidenses estaban coludidos en el movimiento (Blaisdell, 1992:192-193). Así se lo hizo saber a Celso Vega, quien escribió un informe al gobiemo de México señalando que se trataba de un complot filibustero, en el que estaban inmiscuidos extranjeros que residían en Baja Califomia.

Por su parte, el grupo armado recibía casi a diario mayores refuerzos, básicamente de norteamericanos (Blaisdell, 1992:140-141). Sin embargo, a pesar de la victoria sobre Celso Vega, la inactividad imperó en el contingente, al grado de que los problemas internos surgieron debido a las presiones que ejercieron principalmente los norteamericanos que deseaban combatir. De hecho, se formo la llamada legión extranjera, comandada por Stanley Williams, quien disputó el mando a José María Leyva hasta que logró destituirlo a fines de marzo (Franco, 1991:235-237). Por su parte, Simón Berthold, el 16 de marzo se había separado de Leyva por ir con 
rumbo al poblado minero de El Álamo. Sin embargo, en las cercanías del lugar tres indígenas, Jorge González, José Higuera "El Pisigué" y Alberto Rodriguez "El Cachora", reconocieron a Berthold por una fotografia que tenían del cabecilla; uno de ellos, el "Cachora", disparó sobre él hiriéndolo en un muslo ${ }^{1}$ (Lopez Portillo, 1956:425). Este grupo tomo el poblado de El Álamo y permaneció allí hasta la muerte de Berthold el 13 de abril. Posteriormente, los norteamericanos Jack Mosby y Sam Wood tomaron el mando del grupo y se sumaron al ataque a Tijuana durante el mes de mayo. De esta forma, desde fines de abril en adelante, fueron norteamericanos quienes dirigieron el movimiento.

Por su parte, Porfirio Díaz envió al octavo batallón de infantería al mando del coronel Miguel Mayol. Las órdenes se reducían a proteger las obras de irrigación que se realizaban en el valle de Mexicali. La lenta movilización de este grupo levantó inconformidad de los habitantes de Ensenada quienes demandaban mayor actividad militar. Lo anterior provocó protestas en contra de Celso Vega, a quien llegaron a acusar de estar coludido con los "filibusteros", como denominaban comunmente al grupo armado. El 8 de abril en un enfrentamiento en las afueras de Mexicali entre las fuerzas de Mayol con las de Stanley Williams, murió este último. Mayol pasó de largo sin tomar Mexicali con destino al Río Colorado donde permaneció hasta fines de mayo, cuando las obras de irrigación habían sido terminadas.

Carl Ap Rhys Pryce, de origen británico, sustituyó en el mando a Stanley Williams. A pesar de que por razones estratégicas Ricardo Flores Magón ordenó que se atacara a Mayol para cobrar prestigio, Pryce decidió marchar hacia Tijuana. El 8 y 9 de mayo, mientras Ciudad Juárez caía en manos de los maderistas, Pryce tomo el poblado de Tijuana, luego de una intensa batalla en la que participaron habitantes del lugar y soldados federales a las órdenes de Miguel Guerrero, quien fue herido y trasladado a un hospital en los Estados Unidos (Aldrete, 1958:59-60).

Mientras tanto Dick Ferris desde los Estados Unidos propuso en dos ocasiones la formación de una república independiente en Baja Califomia. Carl Ap Ryce Pryce, hizo algunos comentarios a los perídicos de San Diego en los que parecía secundar la idea, aunque luego lo negó (Blaisdell, 1992:148-149). De hecho, llegaron a izarse banderas norteamericanas en algunos edificios de Tijuana, lo mismo que una bandera del Partido Liberal Mexicano (PLM). Esto provocó confusión entre algunos de los miembros

I Otra versión de los hechos la da Roger L. Owen (1988), quien asegura que el indígena que disparó sobre Berthold fue Jorge González y no Alberto Rodríguez. 
del PLM y los extranjeros, por lo que hubo algunos enfrentamientos entre ellos. Varios indígenas de la región que se habían unido al movimiento, comandados por Emilio Guerrero, se negaron a aceptar una bandera propuesta por Dick Ferris. Pryce decidió abandonar el movimiento sin dar explicaciones y Jack Mosby quedo al frente del grupo armado. En los periódicos de San Diego aparecieron fotografías de las banderas que se izaron en Tijuana y numerosos mexicanos que residian en el sur de California se trasladaron por barco a Ensenada, con la intención de defender el distrito. El comité de defensores de la integridad nacional, con sede en San Diego, California, organizó los viajes, la compra de armas y la propaganda en contra del grupo de extranjeros que tenían tomada la plaza fronteriza (Archivo General de la Nación).

Para entonces, se habían celebrado los tratados de Ciudad Juárez, en los que Porfirio Díaz aceptó renunciar a la presidencia de la República. Francisco León de la Barra, presidente interino que había sido recientemente embajador de México en Estados Unidos, solicitó permiso al gobiemo de Taft para que tropas mexicanas cruzaran por su territorio hacia Baja California, permiso que fue otorgado. Por su parte Abraham González, seguidor de Madero, envió una comisión para que tratara de llegar a un arreglo con Ricardo Flores Magón; fue precisamente el hermano mayor de éste, Jesús Flores Magón, quien viajó a Los Ángeles, California, para entrevistarse con él, sin lograr un resultado positivo. A Mexicali llegaron José María Leyva y Jesús González Monroy —quienes habían sido cabecillas del magonismo a principios del movimiento y luego habían desertado para unirse a Madero-y posteriormente Carlos Bernstein; este último logró llegar a varios acuerdos el 17 de junio con los insurrectos que allí quedaron (Franco, 1991:245-250). Sin embargo, debido a que el mayor contingente se encontraba en Tijuana, a la confusión reinante en cuanto a la dirigencia del movimiento y a que Ricardo Flores Magón se negó a aceptar los tratados de Ciudad Juárez, Jack Mosby se enfrentó a Celso Vega el 22 de junio, saliendo victorioso este último. Su ejército estaba integrado por el octavo batallón de infantería, la Compañía fija de Ensenada, cuerpos de auxiliares formados por habitantes del distrito y los voluntarios mexicanos que llegaron del sur de California (Aldrete, 1958:77-82).

Los acontecimientos mencionados, durante un buen número de años, fueron considerados tanto por los habitantes de la región como por el gobiemo del centro del país como filibusterismo, hasta que la figura de Ricardo Flores Magón fue retomada por la historiografía de la revolución mexicana y se realizaron investigaciones por varios estudiosos. La conclusión de estos últimos en general ha sido la de exculpar a Flores Magón de 
un movimiento filibustero, conclusión con la que estamos de acuerdo, pero se han olvidado de cómo se presentaron los hechos de 1911 y no se ha puesto atención en por qué fue tomado así por los habitantes de la época, quienes se consideraron defensores de la integridad nacional. Creemos que hay razones para ello y las publicaciones de la época permiten entender los intereses que estaban en juego y el peligro real de que el movimiento magonista se convirtiera en filibusterismo, no por la intención de Ricardo Flores Magon, sino por la propaganda a favor que tuvo el movimiento en algunos diarios con la finalidad de que al triunfo del mismo, Baja California, o una parte de ella, pasara a los Estados Unidos.

\section{LOS AGRICULTORES DE VALLE IMPERIAL Y EL CALEXICO DAILY CHRONICLE}

El Calexico Daily Chronicle en 1911 era editado por Otis B. Tout y pertenecía a la cadena de perídicos de William Randolph Hearst. Este magnate califomiano tenía diversos intereses en nuestro país, principalmente como propietario de tierras en el norte de México, aunque no en Baja California. Desde fines del siglo XIX, pero fundamentalmente hasta el inicio de los años veinte, los editorialistas de sus principales diarios, el San Francisco Examiner y Los Angeles Examiner, fueron los más insistentes en que la península de Baja Califomia pasara a formar parte de los Estados Unidos. Uno de sus principales argumentos era la amenaza japonesa, quienes, según ellos, trataban de apoderarse de Bahía Magdalena para desembarcar allí sus tropas y luego invadir su territorio o cuando menos afectar el paso de sus barcos frente a las costas de México (Keith Chamberlain, 1949:195-213).

Desde 1904, cuando menos, Otis B. Tout fue un promotor constante del Valle Imperial. Pronosticó en diversos momentos la grandeza del área y en sus editoriales impulsó a los granjeros, agricultores y comerciantes, sobre todo de Caléxico, en el desempeño de sus actividades. Incluso, años más adelante, en 1931, publicó un libro titulado Los primeros treinta años. Historia de Valle Imperial (The first thirty years. History of Imperial Valley, Southern California, U.S.A) en el que proporciona una interesante visión acerca del desarrollo del Valle Imperial.

En el periódico, Otis B. Tout registró gran parte de la problemática de la región, el más grave de todos, sin lugar a dudas, era el referente al agua. El Valle Imperial y el valle de Mexicali surgieron como zonas agrícolas a

2 Se realizó una revisión del Calexico Chronicle desde el 1 de enero de 1906. Pudo haber tenido esa función desde antes, pero no se localizaron más ejemplares del periódico. 
partir de las obras de irrigación realizadas con la intención de desarrollar el primero de ellos, es decir, el lado norteamericano. Las condiciones del terreno no hicieron posible que el Río Colorado irrigara satisfactoriamente el Valle Imperial, por lo que se vieron obligados a construir canales del lado mexicano, con el permiso respectivo del gobiemo de Porfirio Díaz (Tout, 1931:20-140). Esto propició que las tierras del valle de Mexicali cobraran importancia y que otro magnate califomiano, Harrison Gray Otis, encabezara 1a Colorado River Land Company, empresa que adquirió de Guillermo Andrade los derechos sobre más de 300000 hectáreas en el delta del Río Colorado. Desde 1904, los intereses de esta compañía fueron en cierta medida opuestos a los agricultores del Valle Imperial, ya que éstos consideraban que la Colorado se beneficiaba con pocos riesgos, mientras que ellos soportaban la carga económica de los gastos realizados. Esta situación aumentaría paulatinamente con el paso de los años, hasta la década de los treinta. Sin embargo fue la empresa de ferrocarril South Pacific, dirigida en Mexicali por Alberto F. Andrade, la que circunstancialmente se convirtio en el principal acreedor de los agricultores de Valle Imperial.

En 1906, por fallas en la construcción de una de los bocatomas que estaban en territorio mexicano, gran parte del valle de Mexicali se inundo, lo mismo que el poblado y zonas ya en producción de Valle Imperial. La California Development Company, que promovió la colonización del lado norteamericano solicitó ayuda económica de su gobierno federal, la que fue aprobada; sin embargo, mientras la ayuda financiera llegaba, la compañía del ferrocamil South Pacific, que estaba interesada en proteger su línea ferroviaria que atravesaba una parte del valle de Mexicali, fue la que realizó el desembolso económico. Esta situación propició un largo enfrentamiento entre la compañía South Pacific y el gobierno federal de Estados Unidos, lo mismo que con los agricultores y granjeros de Valle Imperial, quienes negociaron el pago de las obras de protección que se realizaron. Las reuniones de los mencionados rancheros y la actividad desplegada era constante, por ello, consideraron que tenían derecho sobre territorio mexicano y así lo hicieron manifiesto repetidamente. Incluso, se llegaron a dar incursiones de agricultores norteamericanos que trataban de abrir las bocatomas de lado mexicano para obtener el preciado líquido, tratando de presionar a la compañía del ferrocarril, que les condicionaba el agua a los pagos y los acuerdos logrados paulatinamente (Calexico Chronicle, 1906, 1907, 1908, 1909). Además, cada año, durante el verano existía el peligro de una nueva inundación (Calexico Chronicle, 1907, 1908, 1909, 1910). Debido a ello, solicitaron al presidente William $\mathrm{H}$. Taft apoyo económico para construir canales del lado mexicano que contribuyeran a evitar 
posibles inundaciones. Durante 1910 obtuvieron un millón de dólares del gobierno federal y las obras comenzaron a realizarse en enero de 1911, precisamente cuando las fuerzas magonistas incursionaron en Baja California. Estas obras fueron las que lleg6 a proteger al Octavo Batallón de Infantería, comandado por Miguel Mayol. Por su parte, la Colorado River Land Company se beneficiaba con estas labores sin exponer su capital.

Para Gray Otis y Chandler en el periódico Los Angeles Times, los magonistas eran unos ladrones y bandoleros, porque amenazaban el control de sus propiedades. Para algunos agricultores del Valle Imperial y en especial para el Calexico Daily Chronicle, el magonismo represento la posibilidad de anexar cuando menos el valle de Mexicali a los Estados Unidos. Por ello, el editor de Calexico Daily Chronicle brindo todo su apoyo a los insurrectos, estableció comunicación directa con los hombres que tomaron Mexicali, tuvo correspondencia con Ricardo Flores Magon, defendio a los representantes del magonismo que fueron encarcelados por violar las leyes de neutralidad, acuso al gobierno federal de apoyar a Porfirio Díaz, trató de crear una imagen negativa de las fuerzas comandadas por Vega, Mayol y los auxiliares y finalmente, de manera por demás evidente, propuso la anexión del valle de Mexicali.

El historiador Lowell E. Blaisdell, en su obra The Desert Revolution, afirma que Dick Ferris, quien propuso la compra de Baja California en dos ocasiones, fue menos peligroso que los granjeros del Valle Imperial y señala:

La naturaleza de las actividades de estos caudalosos rancheros está en el corazón del amargo debate sobre el movimiento magonista. ¿Trataron ellos - al facilitar dinero a los liberales e infiltrar aventureros en sus filas- de transformarlos en una fuerza filibustera con la cual adquirir la península? $\mathrm{O}$ por el contrario, temerosos de las ideas radicales de los magonistas acerca de la tenencia de la tierra ¿Lograron arruinarlos con la etiqueta de filibusteros y tratar de obtener Baja California para los Estados Unidos por otros medios? (Blaisdell, 1992:43)

Es de observarse que en las dos preguntas que hace Blaisdell se pone de manifiesto el interés de apoderarse de Baja California. A mi juicio el primer cuestionamiento lleva implícito la respuesta en la etapa inicial, y de alguna forma la segunda en los últimos dos meses del conflicto. Cabe asentar que en un rancho del Valle Imperial, propiedad del Sr. Edwards, se organizaron los insurrectos antes del ingreso a Mexicali y que algunos norteamericanos como John Bond, y el residente desde hacia algún tiempo en California, Simón Berthold, eran miembros de la Industrial Workers of 
the World $(\mathrm{IWw})^{3}$ y realizaban proselitismo en el Valle Imperial desac tiempo atrás. Esta organización (IWW) fue uno de los pilares del movimiento magonista en una primera etapa (Blaisdell, 1992:43).

Al interés de los agricultores del Valle Imperial por el territorio mexicano, debe sumarse el hecho de las simpatías en general del pueblo norteamericano por la Revolución Mexicana. La obra de John Kenneth Turner, México bárbaro, creó una antipatía en contra de Díaz que se hizo manifiesta al iniciar el movimiento armado (Coerver y Hall, 1984). El grupo que formo el Partido Liberal Mexicano, se beneficio del sentimiento público norteamericano y varios de los individuos que integraron su ejército desconocían, por ejemplo, las diferencias ante el magonismo y el maderismo. Carl Ap Rhys Pryce, uno de los que encabezó el movimiento en el periodo en que los extranjeros estuvieron al frente, es el caso más conocido. De origen Galés, era un mercenario de trayectoria. Estuvo en la guerra de los boers en Sudáfrica y posteriormente fue miembro de la policía montada de Canadá. En la Colombia Británica leyó México bárbaro y a principios de enero de 1911 las noticias de la revolución en México lo motivaron a unirse a la lucha social. En Los Ángeles se incorporó al servicio de la junta del Partido Liberal y ya como líder del grupo, en una entrevista que le hicieron, dijo estar "peleando, sin sentimentalismo, para ayudar a los peones a obtener sus derechos según la constitución de $1836 .$. ó 1858" (Blaisdell, 1992:117), es decir, no sabía cuál. Como él hubo otros tantos, sobre todo cuando el movimiento quedó en manos de norteamericanos. Como ejemplo de ello, se cita una nota del San Diego Sun, (Periódico que favoreciera la anexión) del 11 de mayo, dos días después de la toma de Tijuana, en la que se afirmó que la tropa que avanzaría sobre Ensenada estaba,

compuesta en gran parte por vigorosos jóvenes americanos... su motivo es una mezcla de dos, son llevados por un espíritu de aventuras... pero eso no es todo. Han leído México Bárbaro; sus ojos están encendidos por el fuego de la Revolución; creen que algo valioso para la humanidad vendrá de la lucha que rueda hoy por todo México (San Diego Sun, 17 de mayo de 1911).

Lo anterior, es información de un periódico que trató de alentar al movimiento armado de Baja California, con la intención de que se anexara la península a los Estados Unidos. Más adelante se mencionarán detalles

3 Lawrence Taylor Hansen hace una amplia explicación de quienes formaban la Iww y otras organizaciones de Estados Unidos que colaboraron con el Partido Liberal Mexicano. 
de esta publicacion. Es interesante observar el entusiasmo con que se hablo de la revolución, hecho que como ya se dijo se manifiesta en la prensa del vecino país.

El editor del Calexico Daily Chronicle, Otis B. Tout, participó en el entusiasmo revolucionario, además de tener como interés de fondo alentar la anexión de cuando menos el valle de Mexicali, lo que terminaria con los problemas del agua para los rancheros del Valle Imperial. El 29 de enero, a pesar de que no se publicaba los domingos, en una edición especial motivada por la insurrección magonista, el Daily Chronicle dio a conocer la noticia de que Mexicali había sido tomada. Otis B. Tout describió las primeras actividades de los magonistas, encabezados por José María Leyva y Simon Berthold. Este último, en una entrevista que se realizó en el poblado, dijo que su movimiento formaba parte del que se realizaba en todo México, que eran miembros del Partido Liberal Mexicano y del Partido Socialista Americano y que luchaban contra la tiranía de Porfirio Díaz. Señalo Berthold que las armas las habían comprado en un remate de la armada de Estados Unidos. Otis B. Tout, al mencionar que fue asesinado el alcalde de la cárcel, José Villanueva, dijo que "fue el único muerto en el transcurso de la pacífica toma de Mexicali" (Calexico Daily Chronicle, 29 de enero de 1911). Se aclaró que todos los mexicanos estaban invitados a unirse al movimiento y se colocaron armas en medio de la calle para quien quisiera tomarlas; sin embargo, la mayoría de los habitantes del poblado cruzaron a Caléxico, donde permanecieron hasta el mes de junio en espera de que Mexicali fuera desocupada por los magonistas. De hecho, fueron pocos los residentes del área que se unieron al grupo armado, tal es el caso de Rodolfo L. Gallego, propietario de un rancho en el valle de Mexicali, quien luego de terminado el movimiento siguió en el lugar e incluso fue subprefecto político, posteriormente tomó la bandera del constitucionalismo pero fue derrotado por Esteban Cantú. Años después fue muerto siendo general de la guerra cristera en el interior del país. Dos mujeres, Margarita Ortega y Rosaura Bortari, madre e hija respectivamente, fueron también parte del movimiento, aunque todavía existe poca información que permita identificar su actuación con mayor detenimiento. Margarita Ortega fue asesinada en 1913, por ordenes de Francisco Vázquez, entonces jefe político y militar del distrito. El delito que se le impugnó fue realizar propaganda al Partido Liberal Mexicano y un intento de organizar una revuelta entre los soldados de la guarnición de Ensenada. Hubo también indígenas cucapá que se mantuvieron en contacto con los magonistas, incluso Emilio Guerrero ${ }^{4}$ (Los Angeles Examiner, 15 de octubre de 1911), que se identificó como cucapá, lidereó un grupo de indígenas. 
Las notas de Calexico Daily Chronicle pronto buscaron desprestigiar al ejército federal comandado por Celso Vega y dar una buena imagen de los insurrectos. El 9 y 10 de febrero se publicó información acerca de la primera escaramuza que se realizó en paso de Picachos (actualmente más conocido como la Rumorosa). Otis B. Tout publicó que las tropas de Vega capturaron a dos insurrectos, con los que no se tuvo piedad. A uno de ellos lo mataron instantáneamente, al otro lo hirieron y mantuvieron con vida hasta que pidió un trago de agua; la respuesta fue "aquí está tu trago de agua" y le dispararon a la cabeza (Calexico Daily Chronicle, 10 de febrero de 1911). ${ }^{5}$ Otro ejemplo es cuando, el 18 de febrero, tres días después de que Vega fue derrotado en las cercanías de Mexicali por los insurrectos, se public 6 que el jefe político estaba herido de muerte y las tropas se habian desperdigado - falsas ambas cosas-. Otis B. Tout mencionó que en ocasiones anteriores que Vega visitó Mexicali, había sido déspota y orgulloso, mientras que en esa ocasión tuvo que irse hasta Ensenada sobre dos mulas robadas. Posteriormente, el 5 de abril, el Calexico Daily Chronicle aseguró que en la capital del Distrito, Ensenada, cuarenta soldados federales habían sido eliminados por los insurrectos y que la población estaba dispuesta a aceptar la invasión - ese nombre le dan en la nota de ese díasi les daban la garantía de que sus vidas serían respetadas (Calexico Daily Chronicle, 5 de abril de 1911). La información era falsa, sin embargo la nota ocupaba una parte del encabezado. Con respecto a la batalla del 8 de abril en contra del octavo batallón que encabezaba Miguel Mayol, Otis B. Tout señalo que el combate era injusto, ya que se enfrentaban apenas ochenta insurrectos a cuatrocientos soldados, Indicó que estos últimos con la intención de protegerse de las balas de los insurrectos, cobardemente colocaron en las primeras líneas a niños y a mujeres que los acompañaban; esta información sólo lo maneja este periódico y buscaba fomentar más animadversión entre el público norteamericano hacia el gobiemo de Porfirio Díaz. El domingo 10 de abril, el Calexico Daily Chronicle aseguró que ciento veinticinco soldados se habían sumado a la tropa de Mayol y que era injusto, además de que acusó a los seguidores de Díaz en Caléxico de causar un incendio en Mexicali con la intención de perjudicar la imagen de los revolucionarios (Caléxico Daily Chronicle, 10 de abril de 1911).

\footnotetext{
4 Secretaría de Relaciones Exteriores. L-E 683, recorte del periódico Los Angeles Examiner del 15 de octubre de 1911. En la nota se le menciona como jefe indígena-cucapá. Guerrero declaró que peleaba por la restitución de los terrenos que les habian sido robados por el gobierno de México.

Los dos muertos fueron baleados por Juan de la Cruz Peralta, quien no pertenecía al ejército; se trataba de un ranchero voluntario que encabezó una partida de hombres de la región entre ellos varios indígenas de las rancherias de Tecate.
} 
Días después al notar que Mayol luego de su primer éxito no trataba de tomar Mexicali, lo comparó con una dama que sólo esperaba. El sábado 15 de abril se publicó una nota en la que el general norteamericano Tasker $T$. Bliss que se encontraba entonces en Caléxico, acuso a Mayol de ser un cobarde por no tomar Mexicali, teniendo las condiciones necesarias para ello. Mayol, por su parte, se dirigió a las obras de irrigación que se realizaban en el Río Colorado, siguiendo las instrucciones recibidas en el interior del país, sin volver a atacar a los insurrectos que tenían Mexicali bajo su control. Durante varios días, el Calexico Daily no se ocupó de las tropas de Mayol. El 11 de mayo, dos días después de que Tijuana fue tomada por los insurrectos, aseguró Otis B. Tout que la mitad de los hombres de Mayol estaban ansiosos por desertar y unirse a los revolucionarios. El 12 de mayo afirmó que trescientos hombres de Mayol habian desertado hacia Los Algodones, para unirse en Mexicali con los insurrectos que alli permanecieron a las órdenes de Francisco Quijada. Con la intención de sostener la mentira de los desertores, Tout menciono que éstos no pudieron acercarse debido a que los puentes del ferrocarril South Pacific habían sido destruidos. El 17 de mayo el Calexico Daily Chronicle aseguró que a Mayol sólo le quedaban doscientos hombres. Dos días después, al estar concluidos los trabajos de las obras de irrigación que Mayol custodiaba se inició el regreso a Ensenada. El movimiento del batallón fue interpretado como un posible ataque a Mexicali y según el diario hubo un enfrentamiento en la estación Packard en el que supuestamente los insurgentes rescataron a una mujer, posteriormente encontraron cuatro mujeres que huyeron del octavo batallón, porque según Tout, Mayol dio la orden de que mataran a sus hijos. De acuerdo con esta versión un soldado federal, padre de uno de los pequeños, escapó también en busca de su esposa (Calexico Daily Chronicle, 19 de mayo de 1911). Sin embargo, nunca se dan los nombres de las mujeres y soldados y ninguna otra fuente habla de estos hechos.

En contraparte, los comentarios en apoyo de los magonistas fueron numerosos. Incluso el Calexico Daily Chronicle colaboró con los miembros de la junta del Partido Liberal Mexicano que fueron a platicar con los líderes del movimiento. El propio Ricardo Flores Magón, el 4 de marzo, en Regeneración, escribió que el Calexico Daily Chronicle era una lectura complementaria para los liberales (Blaisdell, 1992:102). Durante los primeros días de la toma de Mexicali, los magonistas tuvieron facilidades de cruzar a Caléxico, California, a comprar mercancías. Sin embargo, la aplicación de las controvertidas leyes de neutralidad afectaron a los insurrectos desde el lunes 13 de febrero. ${ }^{6}$ El Brigadier Tasker T. Bliss, desde San Francisco, Califomia, ordenó que se dejaran de vender mercancías a los 
magonistas en Caléxico, así como también el arresto de cualquiera de ellos que cruzara a los Estados Unidos. José María Leyva tuvo en Otis B. Tout a un excelente emisor de su inconformidad. En los días siguientes, además de publicar el desacuerdo de Leyva hacia la disposición, el Calexico Daily publicó las quejas de los comerciantes de Mexicali, nueve de cada diez de origen norteamericano, que se verían afectados por las órdenes de Bliss (Calexico Daily Chronicle, 10 de febrero de 1911). Además se cuestionaba el hecho de que la prohibición no incluía a las fuerzas del gobiemo mexicano. Dos días después del primer enfrentamiento entre los insurrectos y las tropas de Celso Vega, Otis B. Tout, acompañado de John Kenneth Turner, visitó Mexicali. Hablaron con José María Leyva, quien manifestó no entender las razones por qué le tenían prohibido adquirir mercancías. Turner hizo suya la duda y la planteo ante las autoridades de Estados Unidos, ya que no "podía entender qué ley da derecho a unos americanos a venderle a unos y a otros no" (Calexico Daily Chronicle, 17 de febrero de 1911). En abril, desde San Francisco, Turner mantuvo su campaña en contra de la disposición mencionada y el Calexico Daily publicó artículos en referencia con ello.

La relación entre José María Leyva con el editor del periódico fue cercana. Le concedió varias entrevistas además de permitirle en más de una ocasion visitar el campamento establecido a las afueras de Mexicali. Las declaraciones de Leyva y Berthold que se publicaron fueron en el sentido de que los revolucionarios no tomarían nada sin pagarlo y que nadie sería molestado ni en su persona ni en sus intereses, siempre y cuando no se identificaran o tomaran acciones en favor del gobierno de Porfirio Díaz (Calexico Daily Chronicle, 31 de enero de 1911). Por lo que sabemos estas eran las instrucciones de Ricardo Flores Magón y de acuerdo con varios autores, al principio se cumplió al pie de la letra (Franco, 1991:203-220). A mediados de febrero, cuando lleg 6 el general Tasker T. Bliss a reconocer el área, el Departamento de Estado de Estados Unidos opinó que el movimiento había degenerado en guerrilla y consideró irresponsables a los insurgentes. Otis B. Tout defendió a los revolucionarios señalando que no se había confiscado ninguna propiedad, que no se molestó a las mujeres y el ganado en su totalidad era respetado, afirmó que se podían recorrer las calles de Mexicali sin ningún problema. Señaló que un ciudadano norteamericano había puesto una bandera estadunidense en una tienda de su propiedad y los insurgentes le pidieron que colocara la bandera Para conocer más acerca de las dificultades y ambivalencias en la aplicación de las leyes
de neutralidad véase Don M. Coerver y Linda B. Hall (1984:167). 
mexicana sobre la de Estados Unidos, porque ellos no peleaban contra la bandera mexicana sino contra el gobierno. Asimismo, Tout publicó que el Departamento de Estado parecía querer apoyar a Porfirio Díaz (Calexico Daily Chronicle, 15 de febrero de 1911). Después de la batalla del 15 de febrero, el propio Tout formó parte de una comisión de la Cruz Roja para ir a recoger a los heridos del campo de batalla y trasladarlos a Caléxico para su atención. En un principio mencionó que sólo un soldado federal fue recogido; sin embargo, líneas después escribió que los soldados federales, es decir varios, estaban contentos de haber sido capturados por los magonistas porque tenían buena comida (Calexico Daily Chronicle, 16 de febrero de 1911); posteriormente no se vuelve a hacer mención de ellos y en ninguna otra parte aparecen los nombres de los hombres capturados.

Otros casos en que se hizo resaltar la buena actitud de los insurgentes, es cuando el 17 de febrero se publicó acerca de un joven de dieciocho años que pidió a Leyva dejar el movimiento armado, ya que le dijo no saber que es lo que buscaba cuando se incorporo; Leyva contestó que no había ningún problema, que podía retirarse y fuera un buen muchacho. Poco después, a mediados de abril cuando Carl Ap Rhys Pryce estaba al frente del grupo armado se presento un caso semejante. El estadounidense C.D. Stewart miembro de las fuerzas insurrectas, recibió un telegrama en el que se le informó que su madre tenía un problema en el corazón y el mencionado Stewart manifestó su interés por querer estar con ella, Pryce de inmediato le dio permiso en espera de buenas noticias acerca de la madre del combatiente (Calexico Daily Chronicle, 17 de abril de 1911).

Un aspecto que llama la atención es el interés de Tout por demostrar el resultado positivo de la incursión. Hizo referencia constante a que nuevos hombres se sumaban a la lucha, y poco se asienta de los que abandonaron el movimiento por las diferencias internas que se presentaron. Otis B. Tout sí menciona los problemas que concluyeron con el liderazgo de norteamericanos, ya que tanto los miembros de la rww como los que no lo eran preferian ser comandados por uno de sus compatriotas, como fue el caso de Jack Mosby, Sam Wood, Stanley Williams o uno de origen Galés, como Carl Ap Rhys Pryce. ${ }^{7}$ Sin embargo, las disputas que se dieron por el mando no fueron resaltadas ni comentadas en especial,

7 Para conocer las diferentes revueltas que se presentaron entre los miembros del contingente armado, véase Lowell L. Blaisdell (1992:59-189). Cabe mencionar que Jack London, uno de los intelectuales norteamericanos que apoyó a los magonistas, dijo ser primero hombre de raza blanca, antes que socialista. Incluso llegó a mencionarse la posibilidad de formar una utopía socialista en Baja California integrada exclusivamente por blancos (ver Blaisdell, 1992:47). 
sino que se publicaron las dificultades entre José María Leyva y Stanley Williams por un lado, y entre Francisco Vázquez y Stanley Williams por otro, sin darles importancia. Incluso, después de que Williams efectuó algunas confiscaciones de bienes en el valle de Mexicali, sin tomar en cuenta las órdenes de la junta del Partido Liberal, se le llego a mencionar como bandolero, aunque luego del enfrentamiento con el octavo batallon el 8 de abril, en el que fue berido y murió el día 9 en Caléxico, se le reconoció por su valentía en el combate. El Calexico Daily Chronicle, manifestó que a pesar de la ventaja, 70 contra 400 , Stanley Williams había comprometido seriamente a las tropas federales (Calexico Daily Chronicle, 10 de abril de 1911).

Un ejemplo de cómo Otis B. Tout trató de dar buena impresión del movimiento fue el caso de Simón Berthold. Este general magonista dejo Mexicali el 14 de marzo junto con José María Leyva, hacia Tecate, lugar que Luis Rodríguez tomó el 12 de marzo en nombre de la causa magonista. Leyva y Berthold se separaron el 16, este último se dirigí al poblado minero El Álamo. En la ranchería de Santa Catarina, Berthold y sus hombres fueron avistados por tres indígenas, uno de ellos, Alberto Rodríguez el "Cachora", disparó sobre Berthold hiriéndolo en un muslo. Como consecuencia de ello Berthold murio el 13 de abril en el poblado de El Álamo, a pesar de las atenciones recibidas por el doctor A.L. Foster (Lopez Portillo y Weber, 1956:428-429). El Calexico Daily Chronicle se mostró escéptico a esta noticia y en varias ocasiones informó de los inexistentes combates de Simón Berthold. Uno de los hombres que iba con Berthold, de apellido McDonald, regresó a Mexicali e informó que Berthold se disparó solo en la piema. Aseguró que tomaron el poblado de $\mathrm{El}$ Álamo y confiscaron 18000 dólares de la tienda de José María Beltrán, y que para el 31 de marzo se esperaba el regreso de Berthold (Calexico Daily Chronicle, 27 de marzo de 1911), El 1 de abril se informó que Berthold tuvo gran éxito en El Álamo, su esposa estaba con él, había conseguido caballos, dinero, comían carne, bebían y vestían buena ropa. Sin lugar a dudas, una versión diferente a lo que sucedió.

Berthold murió en medio de intensos dolores y al parecer bebió mucho alcohol durante sus últimos días. Cabe asentar que la mujer que lo acompañó era una enfermera, no su esposa. En los días siguientes el Calexico Daily afirmó que estaba sano y se le había visto combatir en Mexicali el 8 y 9 de abril contra el octavo batallón. El 19 de abril, Otis B. Tout, afirmó que Berthold estaba a punto de tomar el puerto de Ensenada (Calexico Daily Chronicle, 19 de abril de 1911). Finalmente, el 24, se dio a conocer su muerte. En la misma nota se publicó que el sucesor era el general Jack Mosby, hijo del famoso general Mosby de la guerra civil. 


\section{EL BOICOT DE LOS GRANJEROS Y COMERCIANTES DE CALÉXICO}

El apoyo del Calexico Daily Chronicle fue muy evidente para los habitantes del Valle Imperial, así como para los mexicanos que se pasaron a vivir a Caléxico. Luego de revisar la información, detectamos que existió una doble postura manifiesta por los norteamericanos del área con respecto al grupo armado que tenía Mexicali bajo su control. En un principio el apoyo fue evidente, tanto de algunas autoridades como de los habitantes. Posteriormente, el rechazo se puso de manifiesto, no sólo al movimiento en sí, sino también ante el Calexico Daily, al que boicotearon a fines de abril, además de solicitar la intervención armada al presidente Taft para que se restableciera el orden.

Durante los primeros días de la incursión magonista, Caléxico tuvo numerosos visitantes. Las fotografías de los insurrectos se comenzaron a vender desde el primero de febrero. Otis B. Tout, anunciaba en su periodico y en repetidas ocasiones señaló que se trataba de las últimas que se habían obtenido, lo que hace suponer que había compradores que esperaban las imágenes de los insurrectos. En varias ocasiones, cuando hubo rumores de que realizarían combates hubo cientos de espectadores en Caléxico, quienes se retiraban defraudados al no presenciar el combate esperado. Cuando se efectuaron las batallas, los espectadores, desde arriba de los techos de las casas de Caléxico, aplaudían las acciones de los revolucionarios (Calexico Daily Chronicle, 1,4,6,8,13,14,15 y 16 de febrero de 1911). Después del primer combate en contra de las fuerzas dirigidas por Celso Vega, habitantes de Caléxico se organizaron para visitar el campo de batalla, ayudar a los heridos y recoger "souvenirs", como gorras, balas, rifles, etcétera (Calexico Daily Chronicle, 16 de febrero de 1911). También se festejaron casos como el de Bill Taylor, un veterano de la guerra de los boers que vivía en Caléxico y tenía una barbería en Mexicali, quien proclamó que sería el jefe político de Baja Califomia cuando la revolución terminara. Se convirtió en subteniente de José María Leyva, pero fue herido el 15 de febrero, con el pesar de los habitantes de Caléxico, en el primer combate que se sostuvo a las afueras de Mexicali.

Aunado a este apoyo inicial, hubo un interés de parte de rancheros del Valle Imperial por adquirir propiedades en Baja California, hecho que incrementó en los mexicanos residentes en Baja California la idea de que se trataba de una invasión de carácter filibustero. De hecho, el Calexico Daily Chronicle y los propios líderes del movimiento colaboraron a que la idea se esparciera. El 23 de febrero se publico que Leyva y Berthold aseguraron que su movimiento era independiente de cualquier otro y que 
deseaban establecer un gobiemo autónomo, mencionaron su interés por crear una "utopia" con miembros de la Industrial Workers of the World. Por su parte, Tout señalo: "En las entrevistas se ha usado la palabra 'utopía' to que significa una tierra ideal, con leyes ideales y una clase de ciudadanos" (Calexico Daily Chronicle, 23 de febrero de 1911).

En la misma edición del 23 de febrero, con el título de "Buen programa", Otis B. Tout lanzó la interrogante de que si el tóo Sam pudo pagar al nuevo gobiemo de Panamá por el canal, ${ }^{8}$ estaba en duda que si los insurrectos tomaban Ensenada y establecían un nuevo gobiemo, " $i$ se podría encontrar suficiente dinero para comprar el Valle de Mexicali hasta un poco más allá de la sierra Cucapah?" (Calexico Daily Chronicle, 23 de febrero de 1911). Así, desde la tercera semana de febrero se menciono la posibilidad de adquirir la parte que les interesaba a los rancheros del Valle Imperial. Por lo anterior, cabe preguntar, $\measuredangle$ el apoyo que se dio inicialmente a los magonistas, tenía de trasfondo la posibilidad mencionada? Como señalamos anteriormente, Lowell L. Blaisdell señala el peligro latente que representaron los agricultores del Valle Imperial. Sin embargo, la postura de los agricultores cambió para fines de abril cuando, como ya asentamos, solicitaron al presidente Taft que se iniciara una intervención armada que pacificara a los insurrectos.

En efecto, de acuerdo con la lectura de Calexico Daily Chronicle los habitantes de Caléxico y Valle Imperial, vieron con temor las actividades de los insurgentes, principalmente desde fines de marzo, cuando Stanley Williams, en contra de las órdenes de Leyva formó la legión extrajera y comenz 6 a confiscar bienes de algunos rancheros del valle de Mexicali, quienes en su mayoría vivían en la población de Caléxico, Califomia y cruzaban a trabajar al lado mexicano diariamente. Posteriormente con Carl Ap Rhys Pryce, al mando del grupo armado, que poco caso hacían de las órdenes de Flores Magón, se repetían continuamente las confiscaciones de ganado, ya que como hemos asentado estaba prohibido venderles mercancías en Estados Unidos a los insurrectos, a quienes para estas fechas es inexacto seguir considerando magonistas, dada su composición, liderazgo y desacato de las ordenes que llegaban de la junta del Partido Liberal Mexicano. Las manifestaciones de júbilo no se volvieron a repetir y a fines de abril, un grupo de insurrectos incursionó en el Valle Imperial y tomaron ganado y alimentos en el rancho de W.B. Hammer y en el de Benet. Este hecho determinó que se solicitara ayuda a Taft para terminar con los

8 Panamá se formó como país en 1903, luego de que el presidente norteamericano Theodore Roosevelt influyó en la separación de Colombia. 
hombres de Pryce (Calexico Daily Chronicle, 25 de abril de 1911). Aunque Pryce regresó los bienes tomados en los ranchos de Estados Unidos, los granjeros y comerciantes no se detuvieron. Otis B. Tout intentó calmar los ánimos de los inconformes de Caléxico y trató de convencerlos de las bondades del movimiento armado. Publicó el 28 de abril:

Cuando los insurgentes puedan asegurar el control del territorio de Baja California que está en su poder y garantizar la seguridad de los trabajadores y propietarios el sentimiento en su favor se hará evidente otra vez (Calexico Daily Chronicle, 28 de abril de 1911).

Con ello trató de revitalizar las simpatías de los habitantes de la región y publico algunas notas en las que trataba de justificar su apoyo a los insurrectos. El 2 de mayo, el Calexico Daily Chronicle publicó una nota solicitando a los habitantes de Caléxico, California, que asentaran si apoyaban a los hombres que tenía Mexicali bajo su control. Las dos opciones que se ofrecían eran:

a) yo creo que la insurrección en México está basada en causas justas y si respeta los intereses extranjeros, deberían recibir el apoyo de todos los americanos que aman la libertad.

También apruebo la política de amistad por esta causa que ha mostrado el Calexico Chronicle.

b) No simpatizo con la insurrección en México y creo que debería ser terminada y restaurado el viejo orden de cosas en Baja California bajo la dirección del gobierno de Diaz ${ }^{9}$ (Calexico Daily Chronicle, 2 de mayo de 1911).

En el punto A, claramente el editor del Calexico Daily mencionó su apoyo a los insurrectos, lo que hemos venido señalando. Otis B. Tout envió 395 boletas a los pobladores de Caléxico y sólo recibio 95 respuestas. Aún así, publicó "el 90\% a favor de la Revolución" (Calexico Daily Chronicle, 15 de mayo de 1911). De las 95 respuestas, en noventa se asento el apoyo a la revolución en México - no necesariamente a lo que sucedía en Baja California- y en sólo una se decidieron por la segunda opción. Las otras cuatro respuestas fueron "yo no apruebo su conducta" refiriéndose a Tout,

9 En inglés la encuesta decía:

a) I believe the insurrection in Mexico is founded on just causes and, if conducted with due regard for foreign interests, should receive the support of all liberty loving americans.

I also approve the policy of friendship for this cause shown by the Calexico Chronicle. b) I do nol simpathize with the mexican insurrection and believe that it should be washed and this old order of things restored in Baja California under the direction of the Díaz goverment. 
"yo no creo que usted tenga derecho a intervenir en ello", "no es mi negocio" y un último aseguró que había diferencia entre los insurrectos encabezados por Francisco I. Madero y lo que se llevaba a cabo en Baja California, además de señalar que las dos opciones eran inadecuadas ya que sólo respondían a los intereses del editor. En los siguientes días Tout publicó algunas cartas en las que residentes de Caléxico le recriminaban su apoyo a los insurrectos.

La postura de Otis B. Tout no cambió en los siguientes días, probablemente animado por la toma de Tijuana luego de los combates del 8 y 9 de mayo. Se esperaba que el avance sobre Ensenada redituara buenos dividendos a los hombres que comandaba Pryce. Francisco Quijada se había quedado al frente de un grupo de hombres en Mexicali. El 10 de mayo, El Calexico Daily aseguró que el triunfo era evidente y que ya se hablaba del futuro de Baja California. Su entusiasmo lo llevó a escribir abiertamente sus verdaderas pretensiones, además de tratar de convencer a los agricultores del Valle Imperial de que un gran proyecto estaba en puerta. Aseguró que a pesar del triunfo de los revolucionarios en Baja California, no era posible el establecimiento de un gobiemo socialista y que sin la protección de los Estados Unidos habría un clima de inestabilidad constante, ya que el gobierno de México trataría de recuperar su territorio, por tanto:

\begin{abstract}
Como resultado final, pasaría algo similar a Texas. Los americanos conquistaron Texas, lo hicieron independiente, solicitaron su admisión a la unión y fueron bien recibidos como uno de los grandes estados del oeste. Los americanos están llevando a cabo la guerra en Baja California. Déjenlos que tengan éxito, la hagan independiente y luego pidan su admisión a la unión como deben.

El efecto a lo largo de la frontera será mágico. Caléxico se convertiria inmediatamente en el centro de todo Valle Imperial y con el tiempo estaría al frente de la más grande ciudad en todo el desierto del Colorado; los problemas de agua de Valle Imperial terminarian, la molesta frontera iría a la mitad del río, San Diego repetiría la historia de Los Ángeles; un vasto campo se abriría para el desarrollo, los propios mexicanos del territorio estarian mejor; los intereses extranjeros estarían mejor; el resultado sería la mejoría de toda la región (Calexico Daily Chronicle, 16 de mayo de 1911).
\end{abstract}

Lo anterior, muestra claramente cuál era el verdadero interés de Otis B. Tout, y explica las razones de su apoyo al movimiento. Este tipo de declaraciones dieron pie a que se ligara a Ricardo Flores Magón con intentos de filibusterismo que se dieron, en los que Magón no tenía injerencia directa. De hecho, es muy probable que Magón desconociera la trayectoria de los periódicos de Randolph Hearst y su afán anexionista, 
como desconocía muchos aspectos de Baja California. Incluso, Flores Magón envió algunas cartas a Otis B. Tout, a principios de junio, señalando que no se volverían a cometer depredaciones y solicitaba su ayuda, sin darse cuenta de los fines que perseguía el editor del Calexico Daily Chronicle (Calexico Daily Chronicle, 3 de junio de 1911). Algunos de los que han acusado a Flores Magón de filibusterismo lo hicieron precisamente en función de esta relación que hubo con Otis B. Tout. Como ya asentamos, Flores Magón no parece haberse dado cuenta de los verdaderos motivos del mencionado editor. Prueba de ello es que el 2 de junio, Tout publicó un escrito en el que se disculpó de su actitud anterior. Mencionó que las personas que enviaron cartas haciendo la diferencia entre el movimiento maderista y lo que sucedía en Baja California, estaban en lo cierto. Asentó que la encuesta realizada no permitía diferenciar a quién realmente apoyaban los habitantes de Caléxico. Un aspecto que destaca es que al referirse al movimiento de Madero, siempre se le identificaba por el nombre del líder, mientras que el de Baja California, recibe nombres ambiguos, o señala a los líderes en general y se habla del movimiento de "Pryce, William, Berthold, et al," En los días siguientes, el jefe de los insurrectos en Mexicali, Francisco Quijada, fue llamado bandido.

El cambio de actitud de Otis B. Tout, se debi6 a las presiones de los rancheros de la zona, quienes a su vez también habían cambiado su postura en función de las actividades de los insurgentes. Sin embargo, los acontecimientos a nivel nacional fueron también un motivo para tomar una postura distinta. Luego que el 10 de mayo las tropas de Pascual Orozco tomaron Ciudad Juárez bajo su control, se iniciaron pláticas con representantes del gobierno de Díaz. El 21 de mayo se firmaron los tratados de Ciudad Juárezen los que Porfirio Díaz renunció al poder y quedó Francisco León de la Barra como presidente interino. Con ello, el principal motivo por el que los estadounidenses apoyaban la revolución se eliminó. Otis B. Tout, dejo atrás sus comentarios anteriores y se olvidó de lo relativo a los insurrectos. Los acontecimientos de Tijuana apenas si se mencionaron y se vio con buenos ojos la llegada, otra vez, de José María Leyva quien l labía participado en la toma de Mexicali el 29 de enero y Jesús González Monroy, quien se unió días después, sólo que en esta ocasión llegaron como pacificadores enviados por Abraham González (Blaisdell, 1992:199-220), Hecho paradojico y digno de un análisis posterior.

\section{I,A POSTURA DE OTROS DIARIOS CALIFORNIANOS}

los periódicos californianos jugaron un papel importante en los sucesos de 1911 en Baja California. Permitieron, por un lado, que los insurrectos 
y el ejército federal, conocieran los movimientos del enemigo, o que cuando menos tuvieran cierta información que de otra manera no habrían conocido. Incluso, la cantidad de voluntarios mexicanos que llegaron a Ensenada a apoyar y a defender territorio nacional, se debió a las fotografías que aparecieron en varias publicaciones en las cuales banderas norteamericanas ondeaban sobre edificios de Tijuana. Asimismo, los editoriales de los periódicos revelaron la postura de sus dueños, en relación directa con sus intereses en Baja California. En lo referente al Calexico Daily Chronicle, ya hemos analizado su postura y las fluctuaciones que se presentaron. A continuación se mencionarán a grandes rasgos las posturas de otros periódicos que tenían interés en la región.

Los Angeles Times propiedad de Harrison Gray Otis y su yerno Harry Chandler, fue un periódico en el que sus editorialistas continuamente atribuyeron el nombre de bandoleros y ladrones a los hombres que tomaron Mexicali. La razón no es difícil de averiguar. Los mencionados editores, eran los accionistas más representativos de la Colorado River Land Company, dueña de más de 300000 hectáreas en el valle de Mexicali. Algunos autores han sugerido que los mencionados estaban interesados en apoyar un movimiento filibustero para que los terrenos subieran de valor al formar parte de Estados Unidos. Sin embargo, las declaraciones realizadas por el propio Gray Otis muestran que ellos preferían negociar con el gobierno de México que con el de Estados Unidos, ya que los agricultores del Valle Imperial hubieran minado su poder en corto tiempo. En un informe que rinde el General Tasker T. Bliss al Departamento de Estado Norteamericano, asegura que las confusiones legales con respecto a la tenencia de la tierra, podrían ocasionar litigios bajo las leyes estadunidenses que provocarían numerosos conflictos a los dueños de la Colorado. Luego de una conversación con Gray Otis, Bliss aseguró que:

Los propietarios de grandes intereses americanos en Baja California ven con aprehensión el crecimiento del movimiento actual. No desean que Baja California se separe de México ya sea por anexión directa a Estados Unidos o por la creación de una república independiente la cual, ellos creen, seguiría puntualmente la anexión. Piensan que sus intereses actuales son mejor servidos por el gobierno mexicano que por el de Estados Unidos (Blaisdell, 1992:75-76).

En función de ello, Gray Otis fue el primero en reclamar al presidente Taft el envio de tropas con el fin de proteger las obras de irrigación y por tanto la seguridad de que sus propiedades estarían a salvo de inundaciones y serían, como resultó ser, susceptibles de explotación. Tasker T. Bliss reafirmó que "esta clase de gente desea ardientemente la intervención de 
los Estados Unidos" (Blaisdell, 1992:76). Debido a esta postura, el Calexico Daily Chronicle tuvo enfrentamientos a nivel periodístico con los editorialistas de Los Angeles Times; Otis B. Tout acus 6 a estos últimos de falsear la verdad y defendió a los hombres que tenían Mexicali en su poder, la intención de Tout ya se comentó anteriormente. En otras palabras, podríamos decir que a Gray Otis no le interesaba que Baja Califomia pasara a ser parte de Estados Unidos porque la zona con mayor potencial económico ya era de él y tenía mayor preocupación por lo que pudieran hacer los agricultores de Valle Imperial que el gobierno mexicano.

John D. Spreckels, dueño del San Diego Union, tampoco demostró mucho interés en que Baja California pasara a ser parte de los Estados Unidos, la información que brindó este periódico merece un análisis más detenido, sin embargo, en este espacio nos limitaremos a señalar que al igual que Gray Otis, demandó desde el principio el envío de tropas norteamericanas para cuidar de las obras que se realizaron en el valle de Mexicali. Spreckels había obtenido una concesî́n del gobierno de México para construir una vía de ferrocarril que debía pasar de territorio norteamericano a mexicano y de nuevo a los Estados Unidos, en el área de Tijuana-Tecate. Las obras se estaban realizando cuando se inció la incursión magonista; la toma de Tijuana el 8 y 9 de mayo por los hombres comandados por Pryce, hicieron del San Diego Union un protagonista de los acontecimientos, ya que infinidad de declaraciones fueron publicadas en ese diario; Pryce, lleg $\delta$ a comentar abiertamente a varios reporteros que la idea de la anexión de Baja California a Estados Unidos sonaba bastante bien, pero después se retractó de sus palabras. De igual forma, en el San Diego Union aparecieron las aclividades de Dick Ferris, el promotor californiano que propuso la formación de una república independiente en Baja California. Sin embargo, los editoriales del San Diego Union manifestaron su desacuerdo con el movimiento que se desarrollaba en Baja Califomia. El 11 de mayo, dos días después de la toma de Tijuana, el editorial de este periódico señalaba que "la llamada revolución en Baja Califormia es simplemente otro intento de ciudadanos insolentes de los Estados Unidos para arrebatar territorio a México" (San Diego Union, 11 de mayo de 1911). Se enumeraron varios de los proyectos anteriores de anexar Baja Califormia y se consideró que los sucesos de 1911 formaban parte de un plan más. Esto, afirmó el editorialista, obligó al gobierno de los Estados Unidos a declararse ajeno a las actividades de los filibusteros que se hacían llamar insurrectos. Señalo que de triunfar el movimiento, sólo provocaría una situación embarazosa para las autoridades norteamericanas, "pues ello daría a México los más firmes motivos para protestar con base en los viejos temores surgidos de los honerosos intentos de los 
norteamericanos en el pasado por adueñarse de Baja California" (San Diego Union, 11 de mayo de 1911). Para junio de 1911, cuando ya el movimiento había caído en la confusión, Carl Ap Rhys Pryce dejo el mando a Jack Mosby, quien amenazó con hacer explotar las obras del ferrocarril, por ello, Spreckels nuevamente solicitó el ingreso de tropas norteamericanas a salvaguardar sus propiedades. Además de lo anterior, desde tiempo atrás había la idea de que San Diego en lo particular sé vería afectado si la península de Baja California pasaba a ser parte de los Estados Unidos, ya que las actividades navales se trasladarían hacia el sur. Esta idea es importante destacarla, ya que el San Diego Union, en años anteriores y posteriores, siempre vio con malos ojos los intentos de anexión, además de denunciar y criticar a quienes proponían que Baja California pasara a los Estados Unidos.

El San Diego Sun, el contrario del Union, mostró un interés anexionista. E.W. Scripps, en forma semejante el Calexico Daily Chronicle, aseguró un gran futuro económico para los residentes de San Diego. Aseguro el 11 de mayo "Texas fue conquistado por americanos. Es aún de americanos... si Baja California despertara alguna mañana para encontrar las estrellas y las barras ondeando sobre ella, San Diego sería de repente más que nunca una ciudad de Destino" (Blaisdell, 1992:146). Así, este periodico respondía a un viejo anhelo de sus propietarios y a una tendencia que no se manifestaba por primera vez. En las páginas siguientes mencionaremos los antecedentes de su postura.

\section{LOS INTERESES ANEXIONISTAS: ANTES Y DESPUÉS DE 1911}

La incursión magonista, en la que como hemos visto influyeron otros factores ajenos al Partido Liberal Mexicano, no fue la primera ni la última ocasión en que la prensa californiana se ocupó de la posible anexión de la península de Baja California. Desde 1870, cuando menos, algunos diarios se aventuraron a proponer la adquisición del área, por considerar que los inestables gobiernos del centro del país estarian dispuestos a ello con tal de obtener recursos económicos. Uno de los más conocidos intentos de apropiarse de Baja California a fines del siglo XIX, involucro a los rotativos que hemos venido mencionando. Las condiciones fueron un poco diferentes, pero como se verá, los autores principales, Hearst, Otis, Spreckels y el San Diego Sun, tuvieron un papel relevante desde entonces.

En 1890, el San Diego Union, que aún no era propiedad de Spreckels, y el San Francisco Chronicle, de M.H. D. Young, denunciaron un movimiento filibustero del que formaban parte la mayorfa de los directivos de la Compañía Mexicana de Terrenos y Colonización, mejor conocida 
como Compañía Inglesa (Moyano, 1983:229-233). Esta empresa era concesio-naria de una gran parte del Distrito Norte de la Baja California, con la obligación de colonizar. El San Diego Union no tomó la postura de que Baja California debía anexarse a los Estados Unidos, en cambio denunció que empresarios de Los Ángeles tenían especial interés en la anexión. El San Diego Union destacó que para el desarrollo económico del puerto de San Diego la relación con la compañía colonizadora que había en Baja California era fundamental para su desarrollo. Se manejó además como profecía, que el crecimiento de San Diego se vería limitado, ya que las actividades comerciales y militares que había en el puerto se trasladarían hacia la península, afectando a la población sandieguina (Keith Chamberlain, 1949:145). Los Angeles Times, de Gray Otis, quien todavía no poséa terrenos en Baja California, apoyó a un grupo de comerciantes de Los Ángeles que proponían la compra de la península (Moyano, 1983:225).

El San Diego Sun ya mencionado y el San Diego Informat tenían una postura diferente al San Diego Union. Walter G. Smith, el editor del Sun, y Augustus Merill del Informant, fueron quienes mayor propaganda hicieron en favor de la anexión, además se convirtieron en los cabecillas del intento filibustero. Según ellos Smith sería el presidente de la nueva república y Merill el comandante general. Su plan fracasó pero Smith reconoció haber sido contratado para causar problemas a lo largo de la frontera en espera de recibir un buen pago por su trabajo (Keith Chamberlain, 1949:155). Por su parte, M.H.D. Young, del San Francisco Chronicle, trataba de señalar a Spreckels, quien entonces tenía inversiones significativas en San Francisco, como parte de la conspiración. El San Diego Union también llegó a mencionar lo anterior, pero el magnate californiano compró este periódico y tomó posesión del diario el primero de agosto de 1890, fecha en que dejaron de publicarse artículos en referencia al movimiento filibustero. ${ }^{10}$

Un hecho significativo de estos acontecimientos, fue que los periódicos involucraron al mexicano Manuel Sánchez Facio, ex diputado de oposición a Porfirio Díaz, como uno de los posibles dirigentes del movimiento filibustero. Sánchez Facio era un crítico del porfirismo. Fue enviado a Baja California en 1889 para que informara el cumplimiento de los contratos de colonización de la Compañía Internacional, de origen norteamericano,

\footnotetext{
${ }^{10}$ Donald Chaput y James E. Geager mencionan que las reuniones de la conspiración se llevaban a cabo en el Hotel Coronado de San Diego, propiedad de Elisha S. Babesok, quien tuvo una fuerte relación con los conspiradores y era socio de John D. Spreckles quien en affos posteriores sería conocido como el propietario del mismo hotel. En 1911, Carl Ap Rhys Price hizo sus declaraciones en ese lugar, en las que habló de la posible anexión de Baja California a los Estados Unidos y de lo que se retractó a los siguientés días.
} 
que se encontraba en traspaso a la Compañía Inglesa (ver Piñera, 1983:83112). Sánchez Facio publicó su informe en San Francisco, Califomia, con el nombre de "la verdad sobre Baja California", en el que señaló severas fallas de la colonización que se estaba realizando (Piñera, 1983:98). A pesar de que se le menciona en algunas ocasiones como parte de la conspiración, es más factible que dada su oposición al ingreso de capitales extranjeros a México, tratara sólo de dar a conocer su postura, a que se involucrara en un movimiento de carácter filibustero (Keith Chamberlain, 1949:150-157). Quizá el recuerdo de Lorenzo de Zavala, el mexicano que colaboró ampliamente en la separación de Texas, condujo a los periodistas a buscar otro individuo que se pudiera prestar a sus intereses. Es importante considerar lo anterior a fin de destacar la semejanza de Sánchez Facio con Flores Magón, ya que ambos vieron sus nombres entremezclados en publicaciones de California con intenciones propias de los norteamericanos.

Al iniciar el siglo XX, los periódicos de William Randolph Hearst, San Francisco Examiner, Los Angeles Examiner y en cierta medida el Calexico Daily Chronicle mencionaron repetidamente el interés de que Baja California pasara a ser de los Estados Unidos.$^{11} \mathrm{El}$ avance comercial de los japoneses fue la bandera de los editorialistas de Hearst, quienes insistian en el peligro que representaban los nipones. Bahía Magdalena, en el Distrito Sur de la Baja California, fue el sitio que sirvió de pretextó para una larga campaña anexionista. El San Francisco Examiner insistio que los Estados Unidos estaban dispuestos a comprar la península sólo para tener bajo control la mencionada bahía, la que, según ellos, resultaba el sitio adecuado para establecer una base militar, además de que supuestamente los japoneses también estaban interesados en la adquisición de ese lugar con fines de estrategia militar, fundamentalmente por el desembarco de tropas que allí podría realizarse. Esta conjetura estaba lejos de la realidad debido a la falta de agua potable y las serias dificultades que había para trasladar el líquido, hecho que revela el afán anexionista sin tener fundados conocimientos del lugar que deseaban. Con el inicio de la construcción del canal de Panamá en 1903, la anexión se justificaba aún más, desde el punto de vista de los periódicos de Randolph Hearst. En 1907, propusieron oficialmente al gobierno de Estados Unidos la compra de la península al gobiemo mexicano, incluso se menciono que Enrique C. Creel, embajador mexicano en Ios Estados Unidos, consideró favorable

11 Secretaría de Relaciones Exteriores, exp. 15-9-78. En el expediente aparece una nota publicada por el Calexico Chroricle del 25 de agosto de 1904, en el que el editorialista Otis B. Tout solicitó abiertamente la anexión de Baja California. Véase también exp. 15-11-1, donde aparecen recortes de Los Angeles Examiner. 
la propuesta. Lo cierto es que Porfirio Díaz otorgó la concesión al gobierno de Estados Unidos para que Bahía Magdalena fuera utilizada en el entrenamiento de sus tropas. El 20 de octubre de 1907, el primer escuadrón ingreso a la bahía. A lo largo y ancho de nuestro país se escucharon múltiples críticas a Díaz, el comentario más socorrido fue que la historia de Texas parecía repetirse. Al parecer la bahía no fue muy utilizada por razones de abastecimiento, pero en 1910 el gobierno de Taft se mostró inconforme cuando la concesión no fue renovada. Todo indica que más que el establecimiento de una base militar, les preocupaba que los japoneses tomaran control del sitio.

El San Diego Sun, editado por Walter G. Smith, quien como ya mencionamos había intentado ser presidente de la nueva república en 1890 , promovió en 1902, 1904 y 1906 al candidato demócrata a la alcaldía de San Diego William E. Smythe, quien dentro de sus promesas de campaña menciono que Baja California sería anexada a los Estados Unidos. ${ }^{12}$ Smythe realizó varios mítines en los que propagó su idea, aunque perdio las elecciones en las tres ocasiones. A pesar de ello, Smythe declaro que dedicaría su vida por cumplir con sus metas, entre ellas lo referente a la nexión de la península. Por su parte, el San Diego Union criticó repetidamente a Smythe por sus intenciones, ${ }^{13}$ con lo que mantuvo la línea que hemos señalado al oponerse a la anexión.

Al iniciarse la incursión magonista en enero de 1911, fue el periódico Los Angeles Examiner, de Hearst, el primero en llamar filibusteros al grupo armado (Blaisdell, 1992:65). Algunos autores consideran que se trataba de desprestigiar a los magonistas. Sin embargo, por la actitud posterior de los diarios de Hearst, lo que hace es tratar de inducir a la aventura a individuos que en el terreno de los hechos y dada la confusión reinante en las propias filas del grupo armado, podrian conducir al movimiento a los fines perseguidos desde hacia varios años por Randolph Hearst. Sin embargo, lo que provocaron fue involucrar a Flores Magón, en lo que a los ojos de los bajacalifomianos de la época se trataba de una invasión filibustera. Como ya asentamos en páginas atrás, no era lo que Magón quería, pero sí lo que los editorialistas de Hearst deseaban e intentaron provocar que el movimiento tomara ese cauce. En lo que se refiere al San Diego Sun ya

\footnotetext{
12 Archivo de la Secretaria de Relaciones Exteriores, exp. 15-9-78 y 15-14-1. Notas San Diego Sun en diferentes fechas.

13 Archivo de la Secretaria de Relaciones Exteriores, exp. 15-9-78 y 15-14-1, notas de San Diego Union de diferentes fechas. Los recortes del periódico, tanto del Sun como del Union los enviaba a la Secretaría de Relaciones Exteriores, el cónsul mexicano en San Diego, Joaquín Diaz Prieto.
} 
transcribimos anteriormente que en mayo de 1911 trataron de impulsar el movimiento en forma semejante al Calexico Chronicle, con la finalidad de la anexión.

En años posteriores a 1911, las diferentes posturas con respecto a Baja California se mantuvieron, cuando menos hasta 1920. Los Angeles Examiner fue el principal promotor de que Bahía Magdalena estaba a punto de ser invadida por japoneses, con la aprobación del gobierno mexicano. En marzo de 1912 el diario afirmó erróneamente que 75000 japoneses se encontraban en la bahía; la mayoria eran soldados y otros miles estaban en camino. Una comisión fue al sitio, sólo encontraron dos japoneses que investigaban la factibilidad de establecer una empacadora de pescado (Keith Chamberlain, 1949:206). Sin embargo, la propaganda de Los Angeles Examiner tuvo tanto revuelo que el senado de los Estados Unidos, el 2 de agosto de 1912, tomando como base el caso de Bahía Magdalena, resolvió que ninguna empresa o país de origen no estadounidense podía comprar un puerto en el continente americano sin haberlo informado primero al gobierno de Estados Unidos (Keith Chamberlain, 1949:209). Esta resolución fue considerada como parte de la doctrina Monroe. También demuestra el poder que tenían los periódicos de Hearst a pesar del mal manejo que hacían de la información.

Durante el periodo que Esteban Cantú estuvo a cargo del gobierno del Distrito, 1915-1920, las pretensiones de Hearst continuaron. El senador Henry F. Ashurt, de Arizona, se sumó a la propaganda anexionista, con la finalidad de que el estado que representaba tuviera acceso al golfo de California y con ello se incrementara la actividad económica. El San Diego Union, de manera semejante a años anteriores, no apoyó la anexión y publico artículos sobre la buena labor que realizaba Esteban Cantú, para el enriquecimiento y progreso del Distrito (San Diego Union, 1 de enero de 1920), ${ }^{14}$

Debido a la situación política de México, las relaciones tirantes que mantuvo Cantú con Carranza, y este último con el gobierno de Estados Unidos, Cantú fue objeto de acusaciones de querer ceder el Distrito Norte de la Baja California a Estados Unidos. Sin embargo, como hemos señalado en el caso de Flores Magón, la propaganda que afectó su movimiento, tiene que ver con los intereses opuestos de los norteamericanos en la península.

\footnotetext{
14 Secretaria de Relaciones Exteriores, exp, 17-16-142. Notas del San Diego Union en que Esteban Cantú niega la posibilidad de venta. Ver también a Werne (1991:266), quien afirma en la nota 41: "El editor del San Diego Union, Hebert R. Fox, no encontró elogios suficientes para el gobierno de Cantú".
} 


\section{RICARDO FLORES MAGÓN ENTRE LOS MAGNATES}

En el contexto anterior, es posible observar como los sucesos de 1911 en Baja California se enmarcan en una larga lista de acontecimientos en la que los intereses de los magnates californianos estaban inmiscuidos. Considero que al demostrar los cambios de actitud del Calexico Daily Chronicle y su relación con Hearst, es posible afirmar que su interés en la revolución tenía una doble intención. Por un lado, alentar la revolución, que en esos años era muy popular y para cuando en las filas armadas hubiera un elevado número de extranjeros, proponer abiertamente la separación de Baja California de México y su posterior anexión a los Estados Unidos. Gray Otis y John Spreckels, con intereses diferentes, y no necesariamente en forma coordinada, dieron a conocer las noticias utilizando el nombre de ladrones y revoltosos el primero y el segundo dando espacio a los acontecimientos, pero llamando la atención de tal manera que el gobierno de los Estados Unidos se viera comprometido. Las relaciones de Hearst, Spreckels y Otis con Washington pueden explicar más detalles sobre el tema.

No he tocado lo referente a Dick Ferris, debido a que su caso requiere .e un trabajo aparte. Generalmente se le menciona a Ferris como un payaso n rigante, que sólo buscó hacerse propaganda y alterar el movimiento. Sin eu.jargo, considero, en medio de las circunstancias descritas, más que un cómico, era un refinado experto en el papel que jugaba la información, de lo que sacó provecho personal con la intención de mantener la atención y promocionar las ciudades de la costa californiana con miras al desarrollo comercial que se tendría con la inauguración del canal de Panamá en los años siguientes. Pudo actuar como un payaso, pero su intención era muy seria y sobre todo, fue quien a final de cuentas logro su objetivo: la pubucidad.

En medio de estos intereses opuestos se vio inmiscuido el movimiento de Ricardo Flores Magón. El movimiento se le salió de control paulatinamente. Además, lo más significativo fue que la opinión pública norteamericana simpatizó en términos generales con la revolución en contra de Díaz. Al principio los magonistas y los maderistas fueron apoyados por igual, posteriormente Madero obtuvo el mayor consenso y Flores Magón perdió el apoyo aun de su más ferviente promotor, John Kenneth Turner, La población de Califomia, luego de los tratados de Ciudad Juárez, vio al magonismo en forma despectiva, y fue también el momento en que se incrementó la publicidad de que la incursión tenía el rasgo de filibusterismo, lo que no era intención de Magón, pero que como hemos visto fue una posibilidad real que por suerte no llegó a suceder. 
Por todo lo anterior, se considera que al analizar lo sucedido en 1911 en Baja California es necesario establecer las diversas posibilidades que tuvo el movimiento, ya que hubo una gran cantidad de condicionantes que influyeron en él. No se debe abarcar el tema sólo con lo ya tan trillada discusión de si fue filibusterismo o no, si Magón es traidor o no, o atacar a la gente de Baja California de la época como reaccionarios porfiristas para desacreditarlos. No creo que ninguna de estas respuestas siga siendo valida, como lo fue anteriormente para quienes se ocuparon del asunto. Considero que el movimiento debe ser tratado desde diferentes ángulos para lograr una explicación más profunda. En este caso sólo hemos abordado una posibilidad y aún quedan muchas que requieren ser analizadas en un futuro.

\section{BIBLIOGRAFÍA}

ALDRETE, Enrique. 1958. Baja California heroica. México. Archivo General de la Nación, Fondo Flores Magón, caja 1, expediente 4. BLAISDELL, Lowell L. 1992. La revolución en el desierto (The Desert Revolution), traducción de Eduardo Arellano Elías, Instituto de las Américas.

COERVER, Don M. y Lind B. Hall. 1984. Texas and the Mexican Revolution: a Study in State and Natural Border Policy, 1910-1920. Trinity University Press.

FLORES MAGÓN, Ricardo. 1985. Regeneración. (Prólogo, selección y notas de Armando Bartra), edit. ERA. México.

FRANCO Pedroza, Carlos. 1991. "Los sucesos de 1911", en Mexicali. Una historia. (Jorge Martínez-Lourdes Romero, coordinadores). Instituto de Investigaciones Históricas de la UABC,

KEITH Chamberlain, Eugene. 1949. United States Interests in Lower California, tesis doctoral, University of California, Berkeley.

LÓPEZ PORTILLO y Weber, José. 1956. "La campaña en Baja California en 1911", en Memoria de la Academia Mexicana de la Historia, Tomo $\mathrm{XV}$, núm. 4, octubre-diciembre.

MOYANO Pahissa, Ángela. 1983. "La compañía inglesa", en Panorama Historico de Baja California. (David Piñera Ramírez, coordinador), UABC. Centro de Investigaciones Históricas UNAM-UABC.

OWEN, Roger C. 1988. "Participación indigena en la Revolución del Norte", en Baja California textos de su historia.

PIÑERA, David (coordinador). 1983. Panorama Histórico de Baja California. UABC. 
Secretaría de Relaciones Exteriores, exp. 15-9-78 y 15-11-1, 15-14-1 y 17-16-142.

TOUT, Otis B. 1931. The First Thirty Years. History of Imperial Valley Southern, California, U.S.A. Arts Craft Press, San Diego, California. WERNE, Richard, 1991. "Esteban Cantú y la soberanía mexicana en Baja California", en: Mexicali. Una historia (Jorge Martínez y Lourdes Romero, coordinadores). Instituto de Investigaciones Históricas, UNAM-UABC,

\section{HEMEROGRAFIA}

Calexico Daily Chronicle, ediciones de 1906, 1907, 1908, 1909 Y 1910 29 de enero de 1911 31 de enero de 1911 1 de febrero de 1911 4 de febrero de 1911 6 de febrero de 1911 8 de febrero de 1911 10 de febrero de 1911 13 de febrero de 1911 14 de febrero de 1911 15 de febrero de 1911 16 de febrero de 1911 17 de febrero de 1911 23 de febrero de 1911 27 de marzo de 1911 5 de abril de 1911 10 de abril de 1911 17 de abril de 1911 19 de abril de 1911 25 de abril de 1911 28 de abril de 1911 2 de mayo de 1911 15 de mayo de 1911 16 de mayo de 1911 19 de mayo de 1911 3 de junio de 1911

San Diego Sun, 17 de mayo de 1911

San Diego Union, 1 de enero de 1920

11 de mayo de 1911

Los Angeles Examiner, 15 de octubre de 1911 